\title{
Distribution of $A B O$ and Rhesus Blood Group Phenotypes Among Blood Donors at Bahir Dar Blood Bank, Amhara, Northwest Ethiopia: A Retrospective Cross-Sectional Study
}

\author{
Biruk Legese $\mathbb{D}^{1, *}$ \\ Mikru Shiferaw ${ }^{2, *}$ \\ Workineh Tamir ${ }^{3}$ \\ Tegenaw Tiruneh (D) \\ 'Department of Medical Laboratory \\ Sciences, Debre Tabor University, Debre \\ Tabor, Ethiopia; ${ }^{2}$ Bahir Dar Blood Bank \\ Service, Amhara Regional State Health \\ Bureau, Bahir Dar, Ethiopia; ${ }^{3}$ Department \\ of Medical Laboratory Sciences, Debre \\ Markos University, Debre Markos, \\ Ethiopia
}

*These authors contributed equally to this work

\begin{abstract}
Background: Among the blood group antigens identified, $\mathrm{ABO}$ and Rhesus are the most important in transfusion medicine. ABO blood group antigens are the most immunogenic followed by Rhesus (D antigen). These blood groups' frequency distribution varies among different regions and races of the world. This study aimed to identifying the frequency distribution of ABO blood group and rhesus factors among blood donors in Ethiopia.

Methods and Materials: Aretrospective cross-sectional study was conducted from September 12/2019 to March 18/2021 at Bahir Dar blood bank service. After getting a permission letter from the blood bank, data were collected from the blood bank donor data registration system, and descriptive statistical results were presented in number (frequency) and percentage. A Chi-square test was used to show the difference in the frequency distribution of $\mathrm{ABO}$ and $\mathrm{Rh}$ blood groups among sex and blood donation site.

Results: From 40,053 blood donors, $67.7 \%$ were males and younger donors (within the age range of 18-24 years) account for $63.7 \%$. All donations were from voluntary nonremunerated blood donors. The most common blood group was blood group O (41.5\%) followed by A (29.8), B (23.2\%), and AB (5.5\%). Considering ABO and Rh blood group altogether blood group $\mathrm{O}$ positive with $37.9 \%$ was the predominant blood group followed by A positive (27.2\%), B positive (21.4\%), AB positive (5\%), O negative (3.6\%), A negative (2.6\%), B negative (1.8\%), and $\mathrm{AB}$ negative ( $0.4 \%)$. The majority of study participants were $91.5 \% \mathrm{Rh}(\mathrm{D})$ positive.
\end{abstract}

Conclusion: This study showed that blood group $\mathrm{O}$ was the predominant followed by A, B, and $\mathrm{AB}$ and most of the blood donors' blood groups were Rh-positive (91.5\%). About 68.9\% of the total donations were from the first time donor.

Keywords: ABO blood group, rhesus factor, frequency distribution

\section{Introduction}

Blood donation is a crucial part of worldwide healthcare. It includes blood collection, testing, storage, and transfusion to the patient. Among tests performed on collected blood for transfusion includes blood grouping and screening for transfusion transmissible infectious diseases. The term blood group refers to the entire blood group system comprising red blood cell (RBC) antigens and a series of genes controlled the specificity of the blood group, which can be allelic or linked closely on the same chromosome. Blood type refers to a particular pattern of reaction to
Correspondence: Biruk Legese; Mikru Shiferaw

Tel +25I943592686; +25I913257|34

Email birukab1979@gmail.com;

mikshifI23@gmail.com 
testing antisera within a given system. About 38 blood group system genes have been recognized and all known alleles sequenced. ${ }^{1,2}$

Among blood group systems identified, ABO (with blood types $\mathrm{A}, \mathrm{B}, \mathrm{AB}$, and $\mathrm{O}$ ) and Rhesus (with $\mathrm{Rh}$ D-positive or Rh D-negative blood types) are the most important in transfusion medicine. ABO blood group antigens are the most immunogenic of all the blood group antigens followed by Rh (D antigen). ${ }^{3}$ The most common cause of death from a blood transfusion is transfusion of incompatible $\mathrm{ABO}$ blood type due to a clerical error. These antigens are expressed on the RBC surface and determine an individual's blood group. ${ }^{4}$ The Austrian scientist Karl Landsteiner discovered A, B, and O blood types in 1900, and Alfred Von Decastello and Adriano Sturli discovered the fourth type AB, in 1902. Karl Landsteiner and Alexander S. Wiener discovered $\mathrm{Rh}$ blood group in the late 1930s. ${ }^{5}$

$\mathrm{ABO}$ and $\mathrm{Rh}$ blood group frequency distribution varies among different regions and races of the world. Blood group A was the most frequent in Japan, while blood group $\mathrm{O}$ was the predominant blood group among Chinese and Americans. ${ }^{6,7}$ A study by Liu et al in China showed that the frequency distribution of blood groups $\mathrm{O}$, $\mathrm{A}, \mathrm{B}$, and $\mathrm{AB}$ was $35.54 \%, 31.90 \%, 24.14 \%$, and $8.42 \%$, respectively. The distribution of the $\mathrm{Rh}(\mathrm{D})$ negative group was found to be $0.55 \%$ among Chinese blood donors. ${ }^{7,8}$ A systematic review study in India revealed that $\mathrm{O}$ blood group $(34.56 \%)$ was the predominant followed by B (34.10\%), A (23.16\%), and AB (8.1\%). Based on Rh type, $\mathrm{Rh}(\mathrm{D})$ positive and $\mathrm{Rh}(\mathrm{D})$ negative population were $94.13 \%$ and $5.87 \%$, respectively. ${ }^{9}$ In the United States of America, the frequency distribution of blood group $\mathrm{O}$ varies from $39.8 \%$ in Asian donors to $56.5 \%$ in Hispanic donors, and the proportion of Rh (D) negative varies from $1.7 \%$ in Asian donors to $17.3 \%$ in White nonHispanic donors. ${ }^{6}$ Blood group A $(43.8 \%)$ was the most frequent and $\mathrm{AB}$ the least frequent, and Rh positivity rate was $85 \%$ in Turkey. ${ }^{10}$

In Tanzania, the most common blood type was blood group O (52\%), followed by blood group A (26\%), blood group B (19\%) and blood group AB (3\%), and 98\% (n = 1773) of participants were Rh-positive. ${ }^{11}$ Studies in Nigeria and Uganda also revealed blood group $\mathrm{O}$ as the most frequent blood group followed by blood group A, B, and $\mathrm{AB}$ was the least frequent blood group. ${ }^{12,13}$ Studies in Ethiopia showed that blood group $\mathrm{O}$ was the dominant blood group followed by $\mathrm{A}, \mathrm{B}$, and $\mathrm{AB}$, and the $\mathrm{Rh}-$ positive blood group account for the highest percentage. ${ }^{14-16}$

The objective of this study was to determine the distribution of $\mathrm{ABO}$ and $\mathrm{Rh}$ blood groups among blood donors at Bahir Dar blood bank. This data is valuable to manage blood availability by blood type since this study showed the $\mathrm{ABO}$ and $\mathrm{Rh}$ blood distribution by donation site.

\section{Methods and Materials}

A retrospective cross-sectional study was conducted on 40,053 blood donor data collected from September 12/ 2019 to March 18/2021 at Bahir Dar blood bank service. The blood bank is located in the capital city of Amhara regional state, Bahir Dar, Ethiopia. The city is situated in northwest Ethiopia 565 kilometers far from Addis Ababa the capital city of Ethiopia. The blood bank serves more than 28 governmental and private health facilities. It has developed its own blood donor data management system which can store data, perform statistical analysis, send a different text to the blood donor like: "thank you for donating blood", "donor blood type", "reminder for next donation, and post-donation counseling".

Blood was collected from voluntary non-remunerated blood donors, through a mobile campaign and at the blood bank, transported to the blood bank by maintaining the cold chain at $2-10^{\circ} \mathrm{C}$ with a cold box. After arrival at the blood bank, blood was arranged by blood unit number and stored in a blood bank refrigerator $\left(2-6^{\circ} \mathrm{C}\right)$. Forward ABO blood grouping was performed by slid method with known antisera (anti-A and anti B). Rh group was determined by test tube method by using anti-D reagents and Coombs test was performed to detect weak D antigen (Mediclone, Mediclone Biotech, India) and reverse blood grouping was performed with known 5\% A and B cell suspension prepared in the laboratory. $\mathrm{ABO}$ and $\mathrm{Rh}$ blood type of the blood donors were registered into the computerized blood donor data management system. The data were collected after getting a seal of approval from Bahir Dar blood bank. The data registered on an excel sheet on the blood bank blood donor data registration system were checked for completeness and transferred into SPSS version 23 for further analysis.

Descriptive statistical analysis was performed to show the frequency distribution, in number and percentage, of $\mathrm{ABO}$ and $\mathrm{Rh}$ blood group among blood donors, and a chisquare test was employed to test the absence of $\mathrm{ABO}$ and $\mathrm{Rh}$ blood group distribution difference by sex, blood 
Table I Age and Sex Distribution of Voluntary Non-Remunerated Blood Donors from September I2/20I9 to March I8/202I at Bahir Dar Blood Bank

\begin{tabular}{|c|c|c|c|c|c|c|c|c|}
\hline & & \multicolumn{6}{|c|}{ Age } & \multirow[t]{2}{*}{ Total } \\
\hline & & $18-24$ & $25-29$ & $30-34$ & $35-39$ & $40-44$ & $>45$ & \\
\hline \multirow[t]{2}{*}{ Sex } & Female & 10,767 & 1115 & 453 & 270 & 168 & 167 & $12,940(32.3)$ \\
\hline & Male & 14,737 & 4765 & 3755 & 1890 & 1009 & 957 & $27,113(67.7 \%)$ \\
\hline \multicolumn{2}{|c|}{ Total } & $25,504(63.7 \%)$ & $5880(14.7 \%)$ & $4208(10.5 \%)$ & 2160 (5.4\%) & 1177 (2.9\%) & II 24 (2.8\%) & $40,053(100 \%)$ \\
\hline
\end{tabular}

donation site, and p-value less than 0.05 were considered as statistically significant. Bonferroni post hoc test was performed to detect which cells from the contingency table are significantly different. The data were collected after getting acquiescence from the blood bank and we used only donor $\mathrm{ABO}$ and $\mathrm{Rh}$ blood group, age, sex, and site of blood donation based on the code given at the blood bank. Other than these we did not use other voluntary blood donor data like name and phone number. All the data were secured, protected, and accessed only by the investigators.

\section{Result}

In this study, which includes 40,053 voluntary nonremunerated blood donors, the majority of blood donors were males (67.7\%), and most of them (63.7\%) were within the age range of 18-24 years (mean age 24.4 years) (Table 1). Students, from universities and high school, account for $56.6 \%$ of the total (Table 2). As to this investigation, most blood donors $(60.2 \%)$ were from the Bahir Dar city administration and $68.9 \%$ of donations were from the first-time donor. A total of 80,567 units of blood were collected from 40,053 blood donors. The most frequent blood group was blood group $\mathrm{O}(41.5 \%)$ followed by A (29.8), B (23.2\%), and AB (5.5\%). Considering ABO and $\mathrm{Rh}$ blood group altogether blood group $\mathrm{O}$ positive

Table 2 Occupational Distribution of Blood Donors from September 12/2019 to March 18/202I at Bahir Dar Blood Bank

\begin{tabular}{|l|c|c|}
\hline Occupation & Frequency & Percent \\
\hline Civil Servant & 7272 & 18.2 \\
Driver & 421 & 1.1 \\
Private worker & 6012 & 15.0 \\
Student & 22,676 & 56.6 \\
Teacher & 459 & 1.1 \\
Unemploy & 2421 & 6.0 \\
Others & 792 & 2.0 \\
Total & 40,053 & 100.0 \\
\hline
\end{tabular}

Table $3 \mathrm{ABO}$ and Rh Blood Group Distribution of Blood Donors from September 12/2019 to March 18/202I at Bahir Dar Blood Bank

\begin{tabular}{|c|c|c|c|c|}
\hline & & \multicolumn{2}{|c|}{$\begin{array}{l}\text { Rh blood Group of Blood } \\
\text { Donors }\end{array}$} & \multirow[t]{2}{*}{ Total } \\
\hline & & Negative (\%) & Positive (\%) & \\
\hline \multirow[t]{4}{*}{$A B O$} & $A$ & $1036(8.7 \%)$ & 10,897 (91.3\%) & II,933 (100.0\%) \\
\hline & $A B$ & 179 (8.2\%) & 2009 (91.8\%) & $2188(100.0 \%)$ \\
\hline & B & 726 (7.8\%) & 8570 (92.2\%) & $9296(100.0 \%)$ \\
\hline & 0 & $|45|(8.7 \%)$ & 15,185 (91.3\%) & $16,636(100.0 \%)$ \\
\hline \multicolumn{2}{|l|}{ Total } & 3392 (8.5\%) & 36,661 (9l.5\%) & $40,053(100.0 \%)$ \\
\hline
\end{tabular}

(37.9\%) was the most predominant blood group followed by A positive (27.2\%), B positive (21.4\%), (91.5\%), AB positive (5\%), $\mathrm{O}$ negative $(3.6 \%)$, A negative $(2.6 \%)$, $\mathrm{B}$ negative $(1.8 \%)$, and $\mathrm{AB}$ negative $(0.4 \%)$. About $91.5 \%$ of the blood donors were $\mathrm{Rh}$ (D) positive and $8.5 \%$ were $\mathrm{Rh}$ (D) negative (Table 3 ).

\section{Distribution of $A B O$ and Rh Blood Groups with Sex and Blood Donation Site} $\mathrm{ABO}$ and $\mathrm{Rh}$ frequency were not significantly different $(\mathrm{P}=0.64)$ between males and females. The proportions of the $\mathrm{B}, \mathrm{O}$, and $\mathrm{AB}$ blood groups were significantly different across blood donation sites $(\mathrm{P}=0.012)$. As compared with others, Meshenti donation site had a significantly higher (46.9\%) and Motta lower (40.4\%) proportion of the blood group O, while Merawi (27.0\%) and Sekela (7.0\%) had a higher proportion of $\mathrm{B}$ and $\mathrm{AB}$ blood group respectively. $\mathrm{Rh}$-positive blood groups were significantly less frequent among donors around Gimjabet (86.3\%) and Durbete $(89.6 \%)$ as compared to other donation sites $(<0.0001)$ (Table 4).

\section{Discussion}

In Ethiopia, even though there are 40 blood banks, blood and blood component supply is in short supply to meet the 
Table $4 \mathrm{ABO}$ and Rh Blood Group of Blood Group Distribution by Donation Site

\begin{tabular}{|c|c|c|c|c|c|c|}
\hline \multirow[t]{2}{*}{ site of Donation } & \multicolumn{4}{|c|}{ ABO } & \multicolumn{2}{|c|}{$\mathbf{R h}$} \\
\hline & A (\%) & $A B(\%)$ & B (\%) & O (\%) & Negative (\%) & Positive (\%) \\
\hline Adet & 296 (30.5\%) & 54 (5.6\%) & 224 (23.0\%) & $398(40.9 \%)$ & $68(7.0 \%)$ & 904 (93.0\%) \\
\hline Bahirdar & 7150 (29.6\%) & 1390 (5.8\%) & $5630(23.3 \%)$ & 9953 (4I.3\%) & 1935 (8.0\%) & $22,188(92.0 \%)$ \\
\hline Bicolo & $42(26.1 \%)$ & $9(5.6 \%)$ & 38 (23.6\%) & 72 (44.7\%) & $7(4.3 \%)$ & 154 (95.7\%) \\
\hline Chagni & 381 (30.1\%) & $62(4.9 \%)$ & 287 (22.7\%) & 537 (42.4\%) & 107 (8.4\%) & 1160 (91.6\%) \\
\hline Dangila & 689 (30.5\%) & $102(4.5 \%)$ & 504 (22.3\%) & 962 (42.6\%) & 206 (9.1\%) & $205 \mathrm{I}(90.9 \%)$ \\
\hline Durbete & 476 (32.5\%) & $74(5.0 \%)$ & $315(21.5 \%)$ & $60 I(4 I .0 \%)$ & 152 (10.4\%) & $13 \mid 4(89.6 \%)^{*}$ \\
\hline Gemejabet & 98 (30.5\%) & I8 (5.6\%) & $68(21.2 \%)$ & 137 (42.7\%) & 44 (I3.7\%) & 277 (86.3\%)* \\
\hline GendaMoy & $382(29.3 \%)$ & $61(4.7 \%)$ & 325 (24.9\%) & $536(41.1 \%)$ & 114 (8.7\%) & 1190 (91.3\%) \\
\hline Kosober & 975 (28.9\%) & $163(4.8 \%)$ & $786_{a}(23.3 \%)$ & I 448 (42.9\%) & 321 (9.5\%) & $305 I(90.5 \%)$ \\
\hline Merawi & $227(26.7 \%)$ & 35 (4.1\%)* & $230(27.0 \%)^{*}$ & $359(42.2 \%)$ & 79 (9.3\%) & 772 (90.7\%) \\
\hline Meshenti & $80(25.6 \%)$ & 15 (4.8\%) & 71 (22.8\%) & $146(46.8 \%)^{*}$ & 31 (9.9\%) & 281 (90.1\%) \\
\hline Mota & 1060 (31.9\%) & 182 (5.5\%) & 735 (22.2\%) & $|34|$ (40.4\%)* & 300 (9.0\%) & 3018 (91.0\%) \\
\hline Sekela & 77 (23.4\%) & $23(7.0 \%)^{*}$ & $83(25.2 \%)$ & I 46 (44.4\%) & $28(8.5 \%)$ & 301 (91.5\%) \\
\hline Total & II,933 (29.8\%) & $2188(5.5 \%)$ & $9296(23.2 \%)$ & 16,636 (4I.5\%) & 3392 (8.5\%) & 36,661 (9l.5\%) \\
\hline
\end{tabular}

Notes: *Donation sites with, significantly, higher or lower proportions of $B, A B, O$, and Rh-positive blood group $(P=0.012$, and $<0.0001$ respectively).

national demand. Bahir Dar blood bank is the outstanding blood bank in the country, which satisfies the need for blood and blood component supply for its catchment health facilities. The need for the determination of the distribution of $\mathrm{ABO}$ and $\mathrm{Rh}$ blood groups arises to maintain the adequacy of safe blood supply.

In this study, which involved 40,053 blood donors at Bahir Dar blood bank, male blood donors accounted for $67.7 \%$, while $32.3 \%$ were females. In line with our finding studies done in Ethiopia (Arba Minch Jima and Debre Tabor) and Tanzania indicated that males were more involved in blood donation than females. ${ }^{11,14,16}$ This might be due to female donors are more likely to be different than male donors due to medical grounds, such as low hemoglobin levels, low body weight, pregnancy, and breastfeeding. Of the total blood donors in our investigation, the younger population (18-24 years) and students were the most common blood donors. The reason behind might be due to this portion of the population are dynamic and easily convinced.

In this investigation, the most common blood group was O (41.5\%) followed by A (29.8), B (23.2\%), and AB (5.5\%) which was in line with other findings showed that blood group $\mathrm{O}$ as the most common followed by $\mathrm{A}, \mathrm{B}$ and AB. ${ }^{13,14,17,18}$ However, a research conducted in Turkey and Pakistan indicated that blood group A was the predominant, ${ }^{19,20}$ while others revealed $\mathrm{B}$ was the most common blood group. ${ }^{21,22}$ This difference in the frequency distribution of $\mathrm{ABO}$ blood group might be due to genetic variations of the study participant.
As to our finding Rh-positive blood group was the most predominant which covered $91.5 \%$ and the rest $(8.5 \%)$ was Rh-negative. Similarly, a study in Debre Tabor, Ethiopia indicated that Rh positive blood group was the most frequent with $92.7 \%$ and the remaining $7.3 \%$ was Rh-negative. ${ }^{14}$ However, a study in Gambela, Ethiopia reported a higher (19.37\%) proportion of Rh-negative. ${ }^{23}$ Considering ABO and Rh blood group altogether, blood group O positive (37.9\%) was the most predominant blood group whereas $\mathrm{AB}$ negative $(0.4 \%)$ was the rarest. Similarly, a study in Ethiopia and Uganda showed $\mathrm{O}$ positive as the most frequent and $\mathrm{AB}$ negative the least blood group, ${ }^{13,14}$ but a study by Jahanpour et al in Tanzania showed A negative (3\%) followed by $\mathrm{B}$ negative and O negative $2 \%$ each. ${ }^{11}$ This study also showed that $\mathrm{ABO}$ and $\mathrm{Rh}$ blood group distribution varies among different blood donation sites so that the local blood bank will make use of this finding to adjust bloodstock by blood type.

\section{Conclusion}

In this study, blood group $\mathrm{O}$ was the most common followed by A, B, AB. Most of (91.5\%) of the blood donors' blood group were Rh-positive. About $68.9 \%$ of the total donations were from the first-time donor. To make these donors regular non remunerated blood donors strong promotion activities are required. Our study also showed that the distribution of $\mathrm{ABO}$ and $\mathrm{Rh}$ blood groups varies among blood donation sites and it will be help full for the blood bank to adjust bloodstock by blood type. 


\section{Abbreviations}

${ }^{\circ} \mathrm{C}$, Degree Celsius; RBC, Red Blood Cells; RH, rhesus factor.

\section{Data Sharing Statement}

All relevant data are included in this document.

\section{Ethical Considerations}

We obtained a permission letter from Bahir Dar blood bank management bodies. Since we used secondary data, written informed consent was not obtained from each study participant.

\section{Consent for Publication}

Consent for publication of this work was found from Bahir Dar blood bank.

\section{Acknowledgments}

We would like to thank Bahir Dar blood bank laboratory staff for their cooperation during the data extraction process.

\section{Author Contributions}

All authors made a significant contribution to the work reported, whether that is in the conception, study design, execution, acquisition of data, analysis, and interpretation, or in all these areas; took part in drafting, revising, or critically reviewing the article; gave final approval of the version to be published; have agreed on the journal to which the article has been submitted, agree to be accountable for all aspects of the work.

\section{Funding}

The authors declared that there is no funding was obtained for this work.

\section{Disclosure}

The authors have declared that no competing interests exist.

\section{References}

1. Smart E, Armstrong B. Blood group systems. ISBT Sci Series. 2020;15:123-150. doi:10.1111/voxs.12593

2. Mitra R, Mishra N, Rath GP. Blood groups systems. Indian J Anaesth. 2014;58(5):524. doi:10.4103/0019-5049.144645

3. Westhoff $\mathrm{CM}$. The Rh blood group system in review: a new face for the next decade. Transfusion. 2004;44(11):1663-1673. doi:10.1111/ j.0041-1132.2004.04237.x

4. Dean L, Dean L. Blood Groups and Red Cell Antigens. Vol. 2. Bethesda, Md, USA: NCBI; 2005.
5. Patel P. Frequency and distribution of blood groups in blood donors in western Ahmedabad-a hospital based study. Natl $J$ Med Res. 2012;2(2):202-206.

6. Garratty G, Glynn SA, McEntire R, et al. ABO and Rh (D) phenotype frequencies of different racial/ethnic groups in the United States. Transfusion. 2004;44(5):703-706. doi:10.1111/j.1537-2995.200 4.03338.x

7. Liao H, Li J. Distribution characteristics of $\mathrm{ABO}$ and $\mathrm{RhD}$ blood groups among the voluntary blood donors in Chongqing: a retrospective study. Medicine. 2020;99(42):e22689. doi:10.1097/ MD.0000000000022689

8. Liu J, Zhang S, Wang Q, et al. Frequencies and ethnic distribution of $\mathrm{ABO}$ and $\mathrm{RhD}$ blood groups in China: a population-based cross-sectional study. BMJ Open. 2017;7(12):e018476. doi:10.1136/ bmjopen-2017-018476

9. Patidar GK, Dhiman Y. Distribution of $\mathrm{ABO}$ and $\mathrm{Rh}$ (D) blood groups in India: a systematic review. ISBT Sci Series. 2020;16 (1):37-48. doi:10.1111/voxs. 12576

10. Dilek I, Demir C, Ali BA, Akdeniz H. ABO and Rh blood groups frequency in men and women living in eastern Turkey. Int $\mathrm{J}$ Hematol Oncol. 2006;30(4):023-026.

11. Jahanpour O, Pyuza JJ, Ntiyakunze EO, et al. ABO and Rhesus blood group distribution and frequency among blood donors at Kilimanjaro Christian Medical Center, Moshi, Tanzania. BMC Res Notes. 2017;10 (1):1-5. doi:10.1186/s13104-017-3037-3

12. Egesie U, Egesie OJ, Usar I, Johnbull TO. Distribution of ABO, Rhesus blood groups and haemoglobin electrophoresis among the undergraduate students of Niger Delta University Nigeria. Niger J Physiol Sci. 2008;23(1-2):5-8.

13. Apecu RO, Mulogo EM, Bagenda F, Byamungu A. ABO and Rhesus (D) blood group distribution among blood donors in rural south western Uganda: a retrospective study. BMC Res Notes. 2016;9(1):1-4.

14. Tiruneh A, Yetneberk T, Gelaw M, et al. Frequency of ABO and Rh blood group distribution at Debre Tabor Blood Bank, Amhara Region, North-Central Ethiopia. A six-year retrospective survey. J Blood Med. 2020;11:357. doi:10.2147/JBM.S266624

15. Tesfaye K, Petros Y, Andargie M. Frequency distribution of ABO and $\mathrm{Rh}$ (D) blood group alleles in Silte Zone, Ethiopia. Egypt J Med Human Genet. 2015;16(1):71-76. doi:10.1016/j.ejmhg.2014.09.002

16. Alemu G, Mama M. Assessing $\mathrm{ABO} / \mathrm{Rh}$ blood group frequency and association with asymptomatic malaria among blood donors attending Arba Minch blood bank, South Ethiopia. Malar Res Treat. 2016;2016:1-7. doi:10.1155/2016/8043768

17. Negash W. ABO and RH blood group type frequencies among students from different ethnic groups at Enchini Secondary School, West Shewa, Oromia Region, Ethiopia. Ethiop J Nat Computat Sci. 2021;1(1):1-12.

18. Andalibi M, Dehnavi Z, Afshari A, et al. Prevalence of ABO and Rh blood groups and their association with demographic and anthropometric factors in an Iranian population: Mashad study. East Mediterran Health J. 2020;26(8):916-922. doi:10.26719/emhj.20.048

19. Torun YA, Kaynar LG, Karakükcü Ç, et al. ABO and Rh blood group distribution in Kayseri Province, Turkey. Turk J Hematol. 2012;29(1):97.

20. Ullah S, Ahmad T. Distribution of ABO and Rh (D) blood groups in the population of District Dir Lower, Khyber Pakhtunkhwa Pakistan. World Appl Sci J. 2015;33(1):123-135.

21. Kaur D, Doda V, Kandwal M, et al. ABO Rh (D) blood group distribution among whole blood donors at two different setups of tertiary care hospitals in North India. Int J Commun Med Public Health. 2016;3(10):2806-2811. doi:10.18203/2394-6040.ijcmph20163365

22. John S. Prevalence of $\mathrm{ABO}$ and Rhesus blood groups in blood donors: a study from a tertiary care centre in South Kerala. Int J Contemp Med Res. 2017;4(11):2314-2316.

23. Golassa L, Tsegaye A, Erko B, et al. High rhesus (Rh (D)) negative frequency and ethnic-group based $\mathrm{ABO}$ blood group distribution in Ethiopia. BMC Res Notes. 2017;10(1):1-5. doi:10.1186/s13104-0172644-3 


\section{Publish your work in this journal}

The Journal of Blood Medicine is an international, peer-reviewed, open access, online journal publishing laboratory, experimental and clinical aspects of all aspect pertaining to blood based medicine including but not limited to: Transfusion Medicine; Blood collection, Donor issues, Transmittable diseases, and Blood banking logistics; Immunohematology; Artificial and alternative blood based therapeutics; Hematology; Biotechnology/nanotechnology of blood related medicine; Legal aspects of blood medicine; Historical perspectives. The manuscript management system is completely online and includes a very quick and fair peer-review system. Visit http://www.dovepress.com/testimonials.php to read real quotes from published authors. 